\title{
Degenerative disc disease (DDD) in 2017. Possible mechanism of action of ozone [abstract]
}

\author{
Maria Angeles Erario, Anibal Grangeat, Eduardo Croce \\ Instituto Argentino de Ozonoterapia (IAOT), Ciudad Autónoma de Buenos Aires, Argentina
}

\section{ABSTRACT}

\section{О OPEN ACCESS}

\section{Citation}

Erario MA, Grangeat AM, Croce EA. Degenerative disc disease (DDD) in 2017. Possible mechanism of action of ozone [abstract]. Proceedings of The World Conference on Ozone Therapy in Medicine, Dentistry and Veterinary. Ancona (Italy). September 22nd - 23rd - 24th , 2017. J Ozone Ther. 2019;3(4):13. doi: 10.7203/ jo3t.3.4.2019.15418

\section{Academic Editor \\ Jose Baeza-Noci, \\ School of Medicine, Valencia \\ University, SPAIN}

\section{Editor}

World Federation of Ozone Therapy, Bolgna, ITALY

\section{Received}

June 17, 2019

\section{Accepted}

December 08, 2019

Published

December 30, 2019

Intellectual Property

Maria Angeles Erario.

This is an open access article distributed under the terms of the Creative Commons Attribution License (CC BY 4.0), which permits unrestricted use, distribution, and reproduction in any medium, provided the original author and source are credited.

\section{Author Information}

Email: angeleserario@iaot.com.ar
Purpose: Shed light on the biological mechanism of ozone in DDD.

The increase in life expectancy in the population brings to the increase of diseases associated with aging: cancer, heart disease, diabetes and low back pain. DDD and osteoarthritis are the most common causes of chronic joint-related disability and disabling pain in adults. Aging of the organism is the result of accumulation of molecular and cellular alterations over time, leading to a physiological and functional decrease of tissues.

Analysis and Discussion. In the IVDs, aging can be schematized in 3 phases: accumulation of damaged bio- molecules, aberrant cellular response to the lesion and loss of structure and biological function. This perspective focuses on considering that the aging mechanisms are senescence, inflammation and oxidative damage.

The IVDs acquire fissures and neo-vascularisation, this causes that the resident cells that are accustomed to the low voltage of oxygen, are exposed to a greater tension of oxygen and therefore to the oxidative stress.

During aging, IVD cells change from the anabolic to catabolic phenotype. There is increased necrosis, apoptosis, and cell senescence.

The NF-kB signal is central in the inflammatory response, stress and injury. There is a chronic activation of NF-kb correlated with oxidative stress and degeneration.

Symptomatic discs have high levels of pro-inflammatory cytokines that are considered targets of NF-kB.

Conclusion. For many years attempts have been made to inhibit the action of NF-kb and other inflammatory targets to mitigate DDD without favourable results. However, ozone is the solution to this problem because it interferes precisely at the level of NF-kB avoiding its chronic activation.

That is why, in DDD there are sustainable improvements on patients, despite the fact that the NMR images show no significant changes. 